\title{
Psychological and Pedagogic Support of Children with Health Limitations
}

\author{
Elena Vasilyevna Ezhovkina ${ }^{1} \&$ Natalia Vladimirovna Ryabova ${ }^{1}$ \\ ${ }^{1}$ Mordovian State Pedagogical Institute named after M. E. Evsevyev, Saransk, Mordovia, Russia \\ Correspondence: Natalia Vladimirovna Ryabova, Mordovian State Pedagogical Institute named after M. E. \\ Evsevyev, 11a Studencheskaya Str., Saransk, Mordovia 430007, Russia. E-mail: dimsh@mail.ru
}

Received: September 26, 2014 Accepted: November 14, 2014 Online Published: March 29, 2015

doi:10.5539/ies.v8n4p60

URL: http://dx.doi.org/10.5539/ies.v8n4p60

\begin{abstract}
The article represented theoretic analysis of the literature on the problem of psychological and pedagogic support of disabled children. It defined the following terms: a successfully adapting disabled child, a model, interaction of specialists, psychological and pedagogic support. The article also determined the key components of a successfully adapting disabled child: personal (includes such features as confidence, adequate self-esteem, and emotional well-being), academic (elementary ideas about himself and the world around, mathematical ideas, grammar basics), and life (general educational, communicative, social and every day knowledge and skills). Besides, it offered a model of interaction between specialists in psychological and pedagogic support of disabled children. The following interrelated components represented the model: the purpose component, the content-related component, the procedural component, and the evaluative and effective component. The article represented the results of the ascertaining, forming, in the control experiment where the evidence indicated that the personality model of a successfully adapting disabled child was developed by the interaction of various specialists (a resource teacher, a speech and language pathologist, and an educational psychologist).
\end{abstract}

Keywords: adaptation, support, model, successfully adapting disabled child, interaction of specialists

\section{Introduction}

In the history of Russia, the attitude to disabled children went through several stages in its development, from complete indifference to admitting and realizing the necessity to reinforce their legal status legislatively The Director of the Institute of Correctional Pedagogy of the Russian Academy of Sciences N.N. Malofeev pointed out that during the latest quarter of the 20th century a new anti-discrimination policy was born; it removed the habitual borders and barriers separating people or limiting their rights by racial, ethnic, religious, gender, or age difference as well as differences in the health status, etc. (Malofeev, 2010). Thus, both in Russia (Malofeev, 2010; Nazarova, 2010) and in foreign countries (Abbott, 2007; Allan, 2006; Al-Rossan, 2012; Mitchell, 2004; Norwich, 2008; Humphrey, 2008; Lynch, \& Irvine, 2009; Rogers, 2013).

We describe disabled children as the ones who have physical or mental deficiencies that prevent them from assimilation of educational standards if no special conditions for receiving the education are created for them (Nazarova, 2000). The category of such individuals includes mental defectives, children with delayed mental development, deaf, hard-of-hearing, tardily deafened, blind, hard-of-seeing children, children with hard speech damages, conspicuous problems of emotional-volitional sphere, with musculoskeletal disorders, and multiple defects (Malofeev, 2010).

Examing the development of education of the children, we see that the increase in the number of disabled children has become obvious. According to the UN, there are approximately 450 million people with the affected mental and physical development in the world which make up one-tenth of. The statistics of World Health Organization indicated Adequate methods, organizational forms of work, purposeful impact on children contribute to overcoming the defects they have. We have attempted to understand the theory and practice in current upbringing, educating, and developing children. We are also looking for the ways of ameliorating pre-school education.

The methodology of the research, the generalized results of which are set forth in the article, consists of the activity approach (Vygotsky, Rubinshtein, \& Engestrom, 1987); the systematic approach (Bespalko \& 
Bertalanffy, 1973; Parsons, 1978) and the personal approach (Kalmykova, Yakimanskaya, \& Freud, 1995; Rogers, 1959); the theory about the unity of the laws of normal and abnormal children's development (Vlasova, Vygotsky, Graborov and others); the general philosophical, general psychological, and special basics of rehabilitation and socialization of disabled children (Abgarian, Bozhovich, Shipitsina and others); the theoretic provisions of theories and concepts disclosing the nature and consistency of adaptation (Celier; Anochin, and Isaev).

On the basis of the performed analysis of the theory and practice of interaction of specialists (Vilshanskaya et al., 2012), we have determined the following contradiction: between the availability of specialists' opportunities to participate jointly in the educational process and their insufficient readiness to the interaction in the circumstances of psychological and pedagogic support of adaptation of disabled children at PEE.

Based on the circumstance and contradiction above the research questions can be described as follows: how do we provide efficient interaction of specialists during pedagogic support of adaptation of disabled children?

In 2009 the Mordovian State Pedagogical Institute set up the Mordovsky Basis Pedagogic Education Center (MBPEC to unite the corporation of professionally oriented subjects of education, which would ensure efficient interaction of education, scientific researches, and innovations for the region development (Ryabova, 2012). One of the most important subdivisions of MBPEC is the Extended Daycare Center (EDC) for recruiting preschoolers and primary scholars. At the same time, this enter is a scientific and testing site allowing performing fundamental and applied scientific researches (Vinokurova, 2012). Seminars, consultations about the issues related to educating, upbringing and developing preschoolers. The children also included disabled children. That is why the task of teachers working in the EDC is to provide for success of including a disabled child in the environment of healthy age mates, i.e. to form basic components of the adaptation success. Therefore, the teachers working in EDC are also responsible for the disabled children.

\section{Methodology}

Generalization of the results of the theoretic analysis of Russian (Anokhin, Pavlov, and Isaev) and foreign (Berry, 1997; Hartmann, 1958; Lynn, 1984; Phillips, 1968) literature gives reasons to state that there is no single understanding of adaptation among the researchers. Biological perspective believed that this is a reconstruction of physiological, biochemical, and other processes (Anokhin, Pavlov, Celier, Sechenov, \& Hensel, 1974); The philosophical perspective claimed that- adaption as a process, was determined in a given historical period. it is further transformed (Durkgeim, Spencer, Sartre, Jaspers, and others); Sociological perspective believes that the adaption is aa process of adjustment to changing conditions and the environment (Andreeva, Dontsov, Dichev, Shpalinsky, and others); Psychological point of view advocates that as the unity of two processes: assimilation and accommodation (Maslow, May, Aulport, Rodgers, Piage, and others); From the pedagogical aspect, the adaption is simultaneous impact of mult-factors including the complex of both subjective and objective factors depending on external circumstances (Isaev, Butkevich, Mudrik, Riabov, Sedova and others). We understand adaptation as a process of the individual's active adjustment to social environments, relations, requirements, types of activity, living mode, etc. (Ezhovkina \& Ryabova, 2012).

We understand a successfully adapting disabled child as a child who has adapted to sufficiently development of his personal, physical, intellectual, and other potentials in the environment.

In order to single out the components of the structure of a successfully adapting child, we have analyzed the works of researchers who described various aspects of children's adaptation to the terms and conditions of the educational establishment. Thus, Dorozhevets who developed the three-component model of the child's adjustment to the conditions of the educational establishment selected academic, social, and personal adaptation as fundamental elements in the model (Dorozhevets, 1994); Solovyova selected organizational, educationally motivational, psychological, and social adaptation (Solovyova, 2012). Kolominsky, and Panko emphasized the following conditions: education success; progress, mastering expertise, knowledge and skills on principle subjects, attitude to labor: position in the structure of interpersonal relations; status, emotional well-being, sociability; social activity: participation in socially useful activity, independence, initiative (Kolominsky \& Panko, 1988). Aleksandrovskaya (1988) defined efficiency of the educational activity, assimilation of the school behavior standards, success of social contacts, and emotional well-being as adaptation components. Thus, the analysis of the above materials shows that researchers mean the child's success in education and life. However, our research targets not a common child but a disabled child. Therefore, when speaking about the adaptation success, we mean the formation of two components: the academic and life components. Malofeev defines the academic component as accumulation of potential opportunities for their active implementation in the present and future. The researcher regards the life component as mastering expertise, knowledge, and skills that the child 
needs right now in his everyday life (Malofeev, 2010). Therefore, the authors selected the peculiarities of children's adaptation in the circumstances of educational establishments, as well as the possibility to form personal background that would help successfully be included in the society, interact with the people around, etc. The correlation between the academic and life components reflects the education peculiarities for each category of disabled children. In addition, special attention is paid to the development of their personal skills. This is what defined our choice of the personal, academic, and life component in the structure of the adapting personality of a disabled child.

The review of the analyses (Malofeev, Nikolskaya,. Kukushkina, Dorozhevets, Solovyova and others) allowed to develop the structural model of a successfully adapting child, which includes the following components: the personal (it includes such features as confidence, adequate self-esteem, emotional well-being that is displayed in the child's attitude to visiting PEE, to the educational activity, and to himself), academic (elementary ideas about himself and the world around, mathematical ideas, grammar basics that help the disabled child to successfully get involved in the social and cultural environment), and life (general educational, communicative, social and every day knowledge and skills that the child needs in his everyday life) components (Ezhovkina, 2013).

This model served as the basis for projecting the educational process at the facilities of the Extended Daycare Center established at MordGPI as a separate structural subdivision that is daily attended by healthily growing and disabled children. Our observation of the activity of children with development problems showed that they had considerable difficulties in the process of joining the group of healthy? That is why there is a necessity to create such conditions that would facilitate their adaptation. One of the conditions is to provide them with the assistance of specialists that includes holding necessary correctional and developing events aiming to overcome the adaptation difficulties, compensate the development abnormalities, and socialize. We will show the possibilities of implementing the specialists' interaction in the process of psychological and pedagogic support of adaptation of the specified category of children on the example of EDC where a unique developing educational environment is created. It includes all components being necessary for the development of children of each age group that provides successful integration of disabled children in the environment of healthy?

The model of EDC specialists' interaction is of interest in our research. We relied on the researches of Kolesnikova who interprets "a model" as an artificially created example in the form of a scheme, description, physical constructions, or formulas, being similar to the object (phenomena) under research and reflecting or representing a structure, features, and relations between the object's (phenomenon's) elements in a simplified form (Kolesnikova, 2005). Taking into account the analysis of psychological and pedagogic literature (Vilshanskaya \& Prilutskaya, 2012), the interaction of specialists implies joint activity related to the child's assistance in order to solve the problems of children's development, education, upbringing, and socialization. In our research, the psychological and pedagogic assistance is interpreted as a comprehensive process including the creation of special conditions for adapting disabled children to the real social life (Ezhovkina \& Ryabova, 2012).

Therefore, taking into account the ideas of Vilshanskaya and Prilutskaya (2012), we have created the model of interaction of specialists related to psychological and pedagogic support of adaptation of disabled children in the EDC, which is a multilevel formation consisting of a number of interrelated and interdependent components: the purposeful, content-related, procedural, and evaluative-effective ones. In the process of implementing this model, a group of subjects are especially important: the mentors, teachers of additional education (the music, physical education, and English teachers), specialists (the speech pathologist, educational psychologist, and teacher-logopedist), children, and parents.

The crucial components represented goals of specialists' activity in the process of projecting the content and technologies of forming a successfully adapting disabled child. In the process of psychological and pedagogic support, the speech pathologist performed the following tasks: first, he selects diagnostics materials for researching methodologies, implements, analyzes, and generalizes them; second, he develops and clarifies individual educational routes; thirdly, he organizes individual subgroup and group classes with children in accordance with the selected programs. The tasks of the educational psychologist include: (a) selection of psychological methodologies, research performance, analysis and generalization; (b) development of correcting and developing programs, trainings; (c) providing other specialists with recommendations related to the organization of work with the child with account of the psychological diagnosis data. The tasks of a teacher-logopedist include firstly, selection of methodologies, examination, analysis, and summary; secondly, development of individual speech correcting and developing programs; thirdly, development of recommendations for other specialists related to the use of rational logopedic actions in the work with the child.

The content-related component aims to regulate the interaction of the goal, content, and process of forming 
successful adaptation components for disabled individuals. This component includes the combination of educational subjects which programs design educational material (chapters, themes, and questions), mastering which contributes to forming adaptation success of disabled children; unveils the system of personal features, knowledge, and skills, which the disabled child masters; is represented by personal, academic, and life aspects.

The procedural component implements the process of interaction between specialists related to forming the components of the successfully adapting disabled child; a) diagnostics (designing and performing diagnostics, examination in order to study the components of successful adaptation, the processing of data in order to make a report on the disabled child, report execution); b) designing (defining the goal and tasks of the activity; planning; joint designing of the individual educational route, the corrective and developing program of the psychological and pedagogic support of adaptation of the disabled child; forecasting and analyzing the support results, etc.); c), the corrective and developing work (organization of the corrective and developing activity of the specialists by applying various kinds of work taking into account the children's interests, needs, and abilities as well as the zone of the closest development, creation of problem situations and other conditions that provide development of cognitive processes, feelings, will, behavioral culture, stimulation of cognitive independence and creative thinking of children, etc.); d), reflection (analysis of adequacy and correspondence of the specialists' activity to the set tasks; efficiency of the applied methods, actions and ways of pedagogic activity as well as organization forms in accordance with the age peculiarities of children). This component includes the combination of forms, methods, and actions related to performing interdependent activity of each education subject.

The evaluative and effective component discloses the result of the specialists' interaction in the process of supporting the adaptation of disabled children. Its result is the successfully adapting disabled child in the society (we have introduced the earlier model of this feature above-personal, academic, and life). The evaluative and effective component allows tracking the learning children's advancement in mastering the readiness to adapt successfully at each stage of education.

The created model of the interaction of specialists of psychological and pedagogic support of adaptation of disabled children was taken as a basis for pilot testing, which took place during the 2011-2012, 2012-2013 academic years and included ascertaining and educatory stages of the pedagogic experiment (totally 30 scholars with speech and hearing disorders, and with developmental delay).

The ascertaining stage of the experiment, in which 30 preschoolers participated, was held at EDC. The methodology consisted of three series of tasks, each of which aimed to research the basic components of the structure of successfully adapting personality of the disabled child. In order to study the elements of the personal component (self-esteem, anxiety, and emotional well-being), we used the Child's Emotional Well-Being in the Kindergarten adaptive methodology of Kucherova, the Ladder anxiety test by Temmle, Dorkey, and Amen. The academic component was studied with the aid of questions that allowed studying the elementary ideas about oneself and about the environment, the mathematic ideas, and the elementary basics of grammar. The life component (general educational, communicative and social, and everyday skills) included the development of practice-oriented tasks.

We developed the following parameters in order to evaluate the adaptation success of disabled children: completeness of the personal, academic, and life components. We used the following criteria in order to evaluate each component: 1) formation of emotional well-being, adequate self-esteem as well as low level of anxiety (the personal component), 2) mastering the total of elementary ideas about oneself and about mathematics and basics of grammar (the academic component), 3) grasp of the combination of general educational, communicative and social, and everyday skills that are necessary for the child in his everyday life (the life component). The specified parameters and criteria are used to define the level of adaptation of disabled children.

\section{Results}

In the process of the generalized analysis of the received results, we have selected four levels of success in adapting the disabled child (high, medium, low and unformed) in the environment of healthy agemates? The results of the ascertaining experiment with the children attending EDC can be allocated as follows: $10 \%$ of children have a high level of adaptation, $20 \%$ of children, a medium level, $70 \%$ of children, a low one, and the last one is children with no level of adaptation. We pay attention to the fact that the majority of disabled children have a low level of adaptation that is characterized by the weakly formed personal component namely: most children have low self-esteem, the high anxiety level, negative emotional well-being; and by the weakly formed academic component, namely the inability to orient in the condition of the set question, lack of entirety, fullness, exactness, consistency, and succession of information statement in the answers; the life component is characterized by the fact that practical skills of disabled children that are necessary in their everyday life are formed weakly. 
Consequently, the results prove the necessity to create special conditions for educating and upbringing disabled children that would allow them to prepare for independent life in the society and adapt in the environment of healthy people successfully.

The educatory stage of the experiment was held in the 2012-2013 academic years. The developed model of specialists' interaction was implemented by such subjects of education as teachers (who create conditions for forming successful adaptation with disabled children) and children (who perform the educational and gaming activity).

In the course of the educatory experiment, we formed a pedagogic team that realized the importance of the specified activity in the socialization of disabled schoolchildren. Implementation of the target component of the model provides the focus of the educational process on the formation of successful adaptation with disabled children. The interaction vividly demonstrated professional interconnection of all PEE specialists in their work with the disabled child. However, the educational psychologist played the coordinator's role in the adaptation of the disabled children in the environment of healthily growing agemates?. The teacher-logopedist and other EDC specialists worked in close contact with each other and strived to the single approach in upbringing each child as well as to the single style of work, as a whole.

We started our joint work with diagnosing the child where the study of the child's speech and psychological development plays an important role; we developed the joint diagnostics methodologies block, examined, generalized, and systemized the examination results; and then, on their basis, specialists made the group conclusion-the report about the child, which is a system document prepared by the specialists of psychological and pedagogic support and being a basics for developing an individual educational route of the Center learner. At this stage, multilevel diagnostics of children where each specialist studied a separate field of action was of great importance. For example, the speech pathologist studied educational and cognitive activity; the field of action of a teacher-logopedist included speech activity; the educational psychologist mainly paid attention to cognitive and emotionally personal development. According to the diagnostics results each specialist described his insight of the learners: the educational psychologist provided psychological insight while the speech pathologist displayed speech pathology insight, and the teacher-logopedist showed logopedic insight. The opinions of each specialist were analyzed, and taking into account the generalized results, characteristics of the child were made.

Afterwards, the educational path was developed. At this stage, diagnostics information received by various specialists was exchanged. In this period, specialists could clarify and concretize the results of the primary diagnostics. The results of the child's examination by the psychologist were obligatorily correlated with the results of other specialists (speech pathologist, etc.). Such comprehensive study of the preschooler allows to start designing his individual educational route as well as to choose forms of work both with parents and with the child. Note that the specialists' conclusion made professionally is a guarantee of successful design and implementation of the program of corrective and developing work with the child.

As we started to plan the correcting and developing activity, we paid special attention to the development of the comprehensive individual development program (individual routes) for the child where we have specified monthly tasks for each specialist, then we scheduled individual occupation of children taking into account the load on the child. In accordance with the received results of the diagnostics and specialists' recommendations, the educational psychologist made up an individual corrective and developing program of the child's development where he specified the methods and actions used in the work with children and the result of each class.

The next step in our work was to perform corrective and developing activity. The work with each child in EDC was organized with account of his individual peculiarities and opportunities. It is related to the diversity of children attending the Extended Day Center (including healthily growing children and disabled children; children attending mass kindergarten and those who have no experience of communicating with teachers; besides, those were children of different age). Therefore, we had to work simultaneously with children who had various abnormalities in their development. Classes were given 3 times per week.

The main studying form included classes that were given both individually and frontally to children of all groups. Frontal forms of work were of great importance, as at such classes, it was possible to organize joint games that provides for interpersonal communication, various types of activity for developing communicative, planning, and the symbolic function of speech. The group form of work helps overcome negativism, unsociability, and other peculiarities of children with speech development disorders, cause their interest to classes by organizing various play and educationally cognitive situations. Frontal classes are held according to a special program talking into account the regional component being comprehensive integrated program for all cycles of the 
teacher's development work related to educating and upbringing preschoolers (Vinokurova et al., 2012).

It is very efficient when the class starts with playful, surprising moments that provide psychological emotional tuning. Articulatory and breath exercises are an obligatory structural component of each class. During our classes, we used various technologies; modeling and playing tales, game technologies, use of sand and grits, information and communication technologies. During all structural components of the class, we effectively used various didactic materials and equipment, for example, the elements of the Spektra didactic set, materials of Montessori and Voskobovich, as well as didactic means hand-made by our learners; an interactive board that allows to work on the Internet. One of the conditions of successful work with children is the environment of the sensory room. For example, at the beginning of studying many children have difficulties at working in front of the mirror and hardly understand instructions. The majority of them have difficulties at orienting in the scheme of their own body; children do not know the notions of right and left sides, parts of the face. Therefore, it is possible to organize the acquaintance with the children's own body and teach to orient themselves in it in the sensory room in front of the Magic mirror. Children can see themselves full length and make sure that their body consists of two entirely similar parts. Using the playing exercises in front of the Magic mirror, children learn to reproduce person's emotional state (gladness, disappointment, surprise) by facial gestures. They gladly turn into various animals displaying their behavior. Active work of facial and body muscles, mimic and pantomimic displaying of feelings provide abreaction of children's emotions and help them to easily relax and loosen up.

As a conclusion, we analyzed the correlation of the specialists' activity to the set tasks, the efficiency of the applied methods, actions, and means of pedagogic activity as well as organizational forms in accordance with the age-specific features of the children. Every week, the educational psychologist discussed the achievements of each child for the past week and in case of necessity made amendments in the individual development programs. This stage supposed qualitative evaluation of the results of the performed corrective impact. Thus, we analyzed data of logopedic and psychological and pedagogic monitoring, then we evaluated the quality of the corrective and pedagogic activity of all specialists, and, based on the results generalization, we defined the ways of its optimization for the next year.

Thus, any EDC specialist was an active participant of each of the specified stages: they performed advanced psychological and pedagogic diagnostics of learners, conducted individual and group classes with children, supported the children during the whole educational period, organized their own work in close contact with all specialists of the establishment. According to the results of the children's diagnostics, the joint work of specialists determines the actual level of the children's development, zone of their closest development, peculiarities of their emotional and personal sphere, etc. i.e. we have performed comprehensive support of each problem child.

The classes with children were held in the individual, subgroup, and frontal forms. It is necessary to note that in the first part of the day, the classes were conducted both by tutors and by the speech pathologist, while in the second part of the day the classes were conducted by the educational psychologist. The speech pathologist conducted classes on speech development, forming elementary quantity ideas and classes on getting to know the surrounding world. The tutors' classes aimed to familiarize children with the surrounding world, imitative activity, constructing, and hand labor. They reinforced the knowledge acquired by the children, worked out abilities to skills automation integrating the correction goals and content into the children's everyday life (in their play and labor activity), into the content of other classes (imitative activity, observation of the environment) as well as into the regime issues.

Specialists interacted during teachers' councils, consultations, trainings, practical seminars. Due to close interaction of all specialists, they provided for a comprehensive development in the following areas: a prospective plan of interaction with specialists, prospective planning of individual work, registers of interconnection with all specialists-the tasks of a specialist's work by periods of children's' education, recommendations on the corrective and developing work.

The results of such work were observed during the control experiment, which included adapted methodology of the ascertaining experiment using similar tasks, but which was more complicated by the structure. The responds and performed tasks were estimated according to the criteria determined in the ascertaining experiment and regarded as correct, partially correct, and incorrect.

The obtained results show that in the process of forming the components of successful adaptation, the tendency to the transfer from the low to higher level of formation was noticed. Thus, the high level of adaptation is attributive to $20 \%$ of children, the medium one to $60 \%$, the low one to $20 \%$, and the last one is not present. The comparative analysis of the results showed that the high level of adaptation could be achieved only under 
specially created conditions.

\section{Discussions}

The analysis of the performed research shows that the problem of the adaptation of a disabled child is urgent in the contemporary world. We have defined the concept of a successfully adapting child as a child who has adapted to full development of his personal, physical, intellectual, and other potentials in the human environment. We have identified the structure of the successfully adapting disabled child: he has personality; he is academic and full of life. In the process of the research, we made up a model of specialists' interaction during psychological and pedagogic support of adaptation of disabled children. The model structure includes the following components: purposeful, content-related, procedural, and evaluative and effective. We have singled out and created the pedagogic conditions, which are correlated to all stages of the process of formation of the activity of specialists in adapting disabled children, starting from setting the goal, its specification in tasks, and ending with regulating and correcting this process, providing final accounting and estimation of the obtained results, which entirely meet the goals and tasks of the developed model.

Therefore, EDC performs the corrective and developing work with disabled children. It is performed due to strong partnership and interaction of supporting specialists. Specialists' joint activity provides for diagnostics of children with various problems in their development, and based on the made conclusions, develops and then implements the program of individual corrective and developing work with them. The activity of the educational psychologist coordinated with other specialists leads to the correction of speech and personal development of children that provides for their efficient inclusion in joint education together with healthily growing preschoolers, and later on-their successfully socialization.

\section{Conclusion}

The performed pedagogic experiments evidence that it is necessary to approach the problem of adapting disabled children to the environment of healthy age mates. The personality of such a child is formed by the interaction of various specialists whose activity aims to form the personal, academic, and life components. We can achieve certain results only in case of efficient interaction of specialists.

\section{Acknowledgments}

The article was prepared with financial support from the Ministry of Education and Science of the Russian Federation using the funds of project 1.2 Solving Comprehensive Problems Related to Forming Teacher's and Psychologist's Professional Competence in Continuing Education of the Program of Strategic Development of MordGPI for 2012-2016.

\section{References}

Abbott, L. (2007). Northern Ireland special educational needs coordinators creating inclusive environments: An epic struggle. European Journal of Special Needs Education, 22(4), 391-407. http://dx.doi.org/10.1080/08856250701650003

Aleksandrovskaya, E. M. (1988). Social and psychological criteria of adaptation in school. In S. M. Grombaha (Ed.), School and psychological health of pupils (pp. 35-37). Moscow: Medicine.

Allan, J. (2006). The repetition of exclusion. International Journal of Inclusive Education, 10, 121-133. http://dx.doi.org/10.1080/13603110500221511

Al-Rossan, F. (2012). Introduction to special education. Amman: Dar Al-fker.

Berry, J. W. (1997). Immigration, acculturation and adaptation. Applied Psychology: An International Review, 46(1), 5-34.

Bertalanffy, L. (1973). General system theory: foundations, development, applications (p. 295). New York City: G. Braziller.

Dorozhevets, T. V. (1994). Psychological peculiarities of school adaptation of kindergarten children. Thesis of Candidate of Science (p. 148). Moscow Pedagogic University, Moscow.

Engestrom, V. (1987). Learning by expanding. An activity theoretical approach to developmental research. Helsinki: Orienta-konsultit Oy.

Ezhovkina, E. V. (2013). Theoretic Basics of Creating the Model of a Disabled Child Adapting Successfully in the Contemporary Society. Russian Scientific Magazine, 1(32), 239-244.

Ezhovkina, E. V., \& Ryabova, N. V. (2012). To the problem of psychological support of adaptation of disabled 
children. Russian Scientific Magazine, 5(30), 84-89.

Freud, S. (1995). A Seventeenth-century demonological neurosis. The Standard Edition of the Complete Psychological Works of Sigmund Freud, 19, 72-105.

Hartmann, H. (1958). Ego psychology and problem of adaptation. New York: International Universities Press. http://dx.doi.org/10.1037/13180-000

Hensel, H. (1974). Grundbegriffe und neuere Aspekte der physiologischen Adaptation. In Kolloquien SFB 122. Marburg, Bd.2, 1-8.

Humphrey, N. (2008). Including pupils with autistic spectrum disorders in mainstream schools. Support for Learning, 23(1), 41-47. http://dx.doi.org/10.1111/j.1467-9604.2007.00367.x

Kolesnikova, I. A., \& Gorchakova-Sibirskaya, M. P. (2005). Pedagogic Designing: Study Guide (p. 288). Moscow: Academy.

Kolominsky, Ya. L., \& Panko, E. A. (1988). For Teachers about the Psychology of Six Year Old Children (p. 190). Moscow: Prosveschenie.

Lynch, S., \& Irvine, A. (2009). Inclusive education and best practice for children with autism spectrum disorder: An integrated approach. International Journal of Inclusive Education, 13(8), 845-859. http://dx.doi.org/10.1080/13603110802475518

Lynn, R. K. (1984). Attitudes and Social Adaptation: A Person-Situation Interaction Approach. Oxford Oxfordshire; Elmsford, N.Y.: Pergamon Press.

Malofeev, N. N., Nikolskaya, O. S., \& Kukushkina, O. I. (2010). Requirements to Structure of Basic Educational Programs. Almanac of Correction pedagogy Institute of Russian Academy of Education, 14, 8-14.

Maloffev, N. N. (2010). Special Educaiton in the Changing World. Russia: Study Guide (p. 319). Moscow: Prosveschenie.

Mitchell, D. (2004). Special educational needs and inclusive education. London: Routledge.

Nazarova, N. M. (2000). Special Pedagogy (p. 519). Moscow: Academy.

Norwich, B. (2008). Dilemmas of difference, inclusion and disability. Oxon: Routledge.

Parsons, T. (1978). Action Theory and the Human Condition. New York: The Free Press.

Phillips, L. (1968). Human adaptation and his failures. New York and London: Academic Press.

Rogers, C. (2013). Inclusive education and intellectual disability: A sociological engagement with Martha Nussbaum. International Journal of Inclusive Education, 17(9), 988-1002.

Rogers, C. R. (1959). A Theory of therapy, personality and interpersonal relationships. In S. Koch (Ed.), Psychology: A study of a Science, vol. III (pp. 184-256). New York: McGraw-Hill. http://dx.doi.org/10.1080/13603116.2012.727476

Ryabova, N. V. (2012). Mordovskiy Basis Center of Basic Education as Innovative Structural Subdivision of Institute. Humanities and education, 2(10), 41-45.

Solovyova, D. Yu. (2012). Factors of First-Graders Adaptation to School. Issues of Psychology, 4, 15-20.

Vilshanskaya, A. D., Prilutskaya, M. I., \& Protchenko, E. M. (2012). Psychological, Medical, and Pedagogic Council in School: Interaction of Specialists in Solving the Child's Problems (p. 256). Moscow: Genesis.

Vinokurova, N. V. (2012). Innovative Model of Practical Preparation of Future Teacher. Humanities and education, 2, 46-48.

Vinokurova, N. V., Vasenina, S. I., \& Ulanova, S. L. (2012). Exemplary regional Program of Preschool Education (p. 113). Saransk: Mordov. State Pedagogic Institute.

\section{Copyrights}

Copyright for this article is retained by the author(s), with first publication rights granted to the journal.

This is an open-access article distributed under the terms and conditions of the Creative Commons Attribution license (http://creativecommons.org/licenses/by/3.0/). 